\section{International Scientific Journal Theoretical \& Applied Science}

p-ISSN: 2308-4944 (print) e-ISSN: 2409-0085 (online)

Year: $2017 \quad$ Issue: $05 \quad$ Volume: 49

Published: 25.05.2017 http://T-Science.org
Gauhar Sarsenbaevna Borankulova TarSU them. M.H.Dulati Ph.D., i.o.dotsent b.gau@mail.ru

Aigul Turyszhanovna Tungatarova TarSU them. M.H.Dulati department Informatics Ph.D., i.o.dotsent at.tu@mail.ru

SECTION 4. Computer science, computer engineering and automation.

\title{
CRYPTOGRAPHIC METHOD OF INFORMATION PROTECTION IN COMPUTER TRAINING SYSTEMS
}

Abstract: The article deals with cryptographic protection of information in computer-based learning systems. A cryptographic method based on the principle of the abstract automaton operation is considered.

Key words: Information security, cryptography, algorithm, value function.

Language: English

Citation: Borankulova GS, Tungatarova AT (2017) CRYPTOGRAPHIC METHOD OF INFORMATION PROTECTION IN COMPUTER TRAINING SYSTEMS. ISJ Theoretical \& Applied Science, 05 (49): 143-145. Soi: http://s-o-i.org/1.1/TAS-05-49-21 Doi: crossef https://dx.doi.org/10.15863/TAS.2017.05.49.21

\section{Introduction}

In connection with the widespread use of automated training systems, electronic textbooks and tests, the question arose about protecting data from unauthorized access. Currently, there are various methods of protection, use of which depends on the specifics of the information and its carriers, but the cryptographic methods are the most widely used, due to their universality in terms of both the implementation methods and presentation forms.

The proposed cryptographic method is uses the principle of the abstract automaton (AA). The original data stream is divided into fixed-length elements that form a sequence of letters (zf) of the input alphabet of the abstract automation $Z=\{z 1, \ldots$, $\mathrm{zF}$. In the process of AA work, a sequence of letters (wg) of the output alphabet $\mathrm{W}=\{\mathrm{w} 1, \ldots, \mathrm{wG}\}$, which is a stream of transformed data from elements of the same length as the elements of the input stream. The automation is specified using the marked transition table. It is necessary that the conditions for the completeness of the transitions and the completeness of the outputs be obeyed. This means that each column of the marked transition table must contain all the letters of the state alphabet $\mathrm{A}=\{\mathrm{a} 1, \ldots, \mathrm{aM}\}$ AA. In addition, to ensure the possibility of reverse transformation, all the alphabets of the automation $\mathrm{Z}$, $\mathrm{A}$ and $\mathrm{W}$ must coincide, and therefore both its transition functions (d) and the output function 1.

Thus, the alphabets $\mathrm{Z}, \mathrm{W}$ and $\mathrm{A}$ can be reduced to a single alphabet like a $U=\{u 1, \ldots, u M\}$. The marked transition table AA can be represented as a square matrix $\mathrm{T}$ of size $\mathrm{MxM}$, where $\mathrm{M}$ is the number of pairwise distinguishable letters of the alphabet U. Each row and column of the matrix $T$ also each of its elements correspond to the letter of the alphabet U.

The following two algorithms are used to implement the proposed cryptographic method.

\section{The direct conversion algorithm}

1. As an initial state AA can be select any state um (for example, u0)

2. From the input sequence of letters $\mathrm{AA}$ is read the letter $u$ uf

3. In the column of the matrix whose number corresponds to the current state um, the letter ug is selected at the intersection with the string whose number corresponds to the value of the letter uf.

4. The output sequence of the letters AA is written with the letter uf

5. As the new current state of um AA, is selected uf

6. If the input sequence of letters AA is not exhausted, otherwise the end of the algorithm

The inverse transformation algorithm

1. As the initial state AA, the same state um is chosen, as in the direct conversion algorithm

2. From the input sequence of letters AA is read the letter ug

3. In the column of the matrix whose number corresponds to the current state um, the letter ug

4. In the output sequence of letters AA is written the letter uf, the value of which corresponds 


\begin{tabular}{|c|c|c|c|c|c|c|}
\hline Impact Factor: & $\begin{array}{l}\text { ISRA (India) } \\
\text { ISI (Dubai, UAF } \\
\text { GIF (Australia) } \\
\text { JIF }\end{array}$ & $\begin{array}{l}=1.344 \\
=0.829 \\
=0.564 \\
=1.500\end{array}$ & $\begin{array}{l}\text { SIS (USA) } \\
\text { PИНЦ (Russia) } \\
\text { ESJI (KZ) } \\
\text { SJIF (Morocco) }\end{array}$ & $\begin{array}{l}=0.912 \\
=0.234 \\
=3.860 \\
=\mathbf{2 . 0 3 1}\end{array}$ & $\begin{array}{l}\text { ICV (Poland) } \\
\text { PIF (India) } \\
\text { IBI (India) }\end{array}$ & $\begin{array}{l}=6.630 \\
=1.940 \\
=4.260\end{array}$ \\
\hline
\end{tabular}

to the number of the line, to the intersection with which the ug letter was found

5. As the new current state um AA, the state is selected ug

6. If the input sequence of letters AA is not exhausted, then the transition will be otherwise end of the algorithm

From the consideration of the two above algorithms, we can conclude that both algorithms use the same encryption matrix $\mathrm{T}$ (the marked transition table AA) and are mutually invertible. In this case, the inverse transformation algorithm in general works slower, since it contains a search operation in the matrix column, whereas in the direct conversion algorithm the sampling operation is used. Since the time for administration in author systems does not play a significant role, it is advisable to use the direct conversion algorithm as an algorithm for decryption, and the reverse transformation of the encryption algorithm.

Let's illustrate the work of algorithms using the alphabet of eight letters as an example. (Figure 1) presents one of the options for constructing a marked transition table in a size matrix $8 \times 8$.

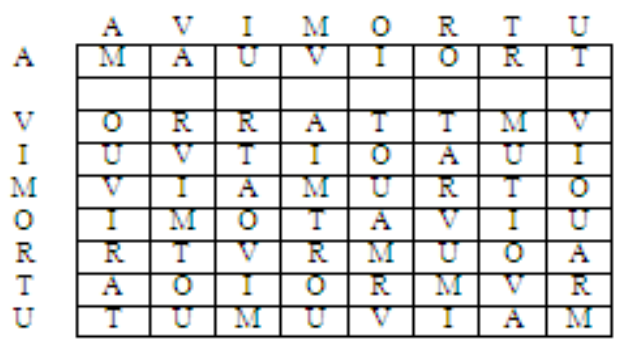

Figure 1 -Work of algorithms using the alphabet of eight letters as an example.

Let's take as an example the words "AVTOMAT" and "MURA". We choose the initial state corresponding to the letter A. Then the encryption process can be presented step-by-step in the form of the following table.

\begin{tabular}{|l|l|l|l|l|l|l|l|l|l|l|l|}
\hline $\begin{array}{l}\text { Step } \\
\text { number }\end{array}$ & 1 & 2 & 3 & 4 & 5 & 6 & 7 & 8 & 9 & 10 & 11 \\
\hline $\begin{array}{l}\text { Read-out } \\
\text { letter ug }\end{array}$ & A & V & T & O & M & A & T & M & U & R & A \\
\hline $\begin{array}{l}\text { Current } \\
\text { state um }\end{array}$ & A & A & V & T & O & M & A & T & M & U & R \\
\hline $\begin{array}{l}\text { Writable } \\
\text { letter }\end{array}$ & T & M & R & R & R & V & U & V & T & T & I \\
\hline
\end{tabular}

Let's try to restore the original form of encrypted words:

\begin{tabular}{|l|l|l|l|l|l|l|l|l|l|l|l|}
\hline $\begin{array}{l}\text { Step } \\
\text { number }\end{array}$ & 1 & 2 & 3 & 4 & 5 & 6 & 7 & 8 & 9 & 10 & 11 \\
\hline $\begin{array}{l}\text { Read-out } \\
\text { letter ug }\end{array}$ & T & M & R & R & R & V & U & V & T & T & I \\
\hline $\begin{array}{l}\text { Current } \\
\text { state um }\end{array}$ & A & A & V & T & O & M & A & T & M & U & R \\
\hline $\begin{array}{l}\text { Writable } \\
\text { letter }\end{array}$ & A & V & T & O & M & A & T & M & U & R & A \\
\hline
\end{tabular}

As a result received words like a "AVTOMAT" and "MURA".

The algorithms examined are fairly simple to implement and allow you to quickly and efficiently encrypt data of any type, including those presented in ASCII- format. As the encryption key is the marked transition table, the total number of different variants of construction is (M!)M variants, and its size, the length of the encryption key is MxM letters.
However, this method has a significant drawback, which in some cases can dramatically reduce the quality of encryption. Since the choice of the new state AA depends on the read letter, the same input sequence. This makes the encrypted information weakly resistant to particular analysis. To neutralize this negative effect, you need to add an additional parameter to the transition function $\mathrm{d}$ AA, independent of the current state um, neither from a letter uf. 


\begin{tabular}{l|lrl|l|ll} 
& ISRA (India) & $=\mathbf{1 . 3 4 4}$ & SIS (USA) & $=\mathbf{0 . 9 1 2}$ & ICV (Poland) & $=\mathbf{6 . 6 3 0}$ \\
Impact Factor: & ISI (Dubai, UAE) $=\mathbf{0 . 8 2 9}$ & PUHL (Russia) $=\mathbf{0 . 2 3 4}$ & PIF (India) & $=\mathbf{1 . 9 4 0}$ \\
& GIF (Australia) & $\mathbf{0 . 5 6 4}$ & ESJI (KZ) & $=3.860$ & IBI (India) & $=\mathbf{4 . 2 6 0}$ \\
& JIF & $=\mathbf{1 . 5 0 0}$ & SJIF (Morocco) & $=\mathbf{2 . 0 3 1}$ & & \\
\hline
\end{tabular}

You can suggest the following way to implement this idea. The output sequence of the letters of the first AA is used as the input sequence of the second AA, whose transition function is independent of (uf and ug), and the output sequence of letters and is the resulting output sequence (Figure 2).

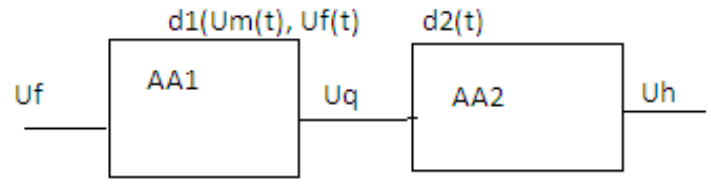

Figure 2 - the output sequence of letters and is the resulting

\section{Conclusion}

In the simplest case, the function $\mathrm{d} 2$ performs the transition of the automaton from the current state to the state immediately following it. In the reverse transformation of data, the automata should be connected in sequence AA2-AA1. Here it is necessary to take into account that the excessive complexity of the transition function $\mathrm{d} 2(\mathrm{t})$ or the connection of additional automatic machines will lead to an increase in the time costs for encryption and decryption.

Thus, the proposed solution allows not only to eliminate the identity of encryption of the same data blocks, but also to increase the total number of variants of the encryption key from the viewpoint of the transition function $\mathrm{d} 2$.

\section{References:}

1. Nesterov S (2009) Information security and information security: Tutorial, - 126p.

2. Proskurin V (2000) Protection in operating systems / V. Proskurin, S. Krutov, I. Mahkevich - Radio and communication.

3. Bezbogov (2007) Operating system security: "Publishing outfit Mechanical engineering-1". 220p.

4. James Foster, Mike Price (2006) Technique of hacking: sockets, exploits, "shell" code: Translation from English, A.Slinkina. - 784p.

5. Babenko L (2015) Modern algorithms of block encryption and methods for their analysis. $376 \mathrm{p}$.
6. Buzov G (2016) Protection of restricted access information from leakage through technical channels. 2016. - 186p.

7. Litvinskaya O (2015) Fundamentals of the theory of information transfer. Tutorial. $-168 \mathrm{p}$.

8. Gorev A. Simakov (2016) Providing Information Security. Moscow. - 494p.

9. Gribunin V (2016) Digital steganography. $589 \mathrm{p}$.

10. Zhdanov O (2015) A technique for selecting key information for the block cipher algorithm. $-869 p$. 